\title{
Should We Pay More Attention to Endotracheal Tube Fixation during Anesthesia-Surveys from Chinese Anesthesiologists for Endotracheal Tube Fixation and Endotracheal Tube Displacement in 2014 and 2020
}

\author{
Dongxue Li, Tongfeng Luo, Chuling Liu, Xi Hong, Sanqing Jin* \\ Department of Anesthesia, The Sixth Affiliated Hospital, Sun Yat-sen University, Guangzhou, China \\ Email: *jinsq@mail.sysu.edu.cn
}

How to cite this paper: Li, D.X., Luo, T.F., Liu, C.L., Hong, X. and Jin, S.Q. (2021) Should We Pay More Attention to Endotracheal Tube Fixation during Anesthesia-Surveys from Chinese Anesthesiologists for Endotracheal Tube Fixation and Endotracheal Tube Displacement in 2014 and 2020. Open Journal of Anesthesiology, 11, 243-258.

https://doi.org/10.4236/ojanes.2021.118024

Received: July 8, 2021

Accepted: August 28, 2021

Published: August 31, 2021

Copyright $\odot 2021$ by author(s) and Scientific Research Publishing Inc. This work is licensed under the Creative Commons Attribution International License (CC BY 4.0).

http://creativecommons.org/licenses/by/4.0/ (c) (i) Open Access

\section{Abstract}

Background: Displacement of endotracheal tube (ETT) can result in endobronchial intubation and accidental extubation that severely threatens safety of surgical patients. However, few surveys have investigated intraoperative ETT displacement experienced by anesthesiologists. The objective of these surveys was to investigate ETT fixation method and ETT displacement during general anesthesia experienced by anesthesiologists in China in 2014 and 2020. Methods: A questionnaire was designed with twenty questions and randomly distributed to anesthesiologists in two survey methods. In 2014, we collected responses from anesthesiologists who participated in the 22nd annual meeting of the Chinese Society of Anesthesiology in a face-to-face setting; in 2020, anesthesiologists from twenty-eight provinces completed the questionnaire through an online questionnaire survey platform. Differences in the responses from the anesthesiologists in 2014 and 2020 were assessed with a chi-square test. Results: In total, 568 questionnaires were collected, of which 541 questionnaires were valid (valid response rate 95.2\%). A majority of the respondents (65.6\%) had experienced ETT displacement, and $4.3 \%$ of respondents had experienced serious complications due to ETT displacement. Three hundred and twenty-nine respondents (60.8\%) fixed the ETT with adhesive tape in the shape of the letter X. A majority of respondents considered the influence of surgical site, body position (97.8\% of all respondents), and age (77.1\% of all respondents) on fixing the ETT. Adhesive tape was the most commonly used material to fix the ETT (90.4\% of the respondents). Conclusion: During clinical anesthesia, a majority of anesthesiologists experienced 
ETT displacement that can result in serious consequences. Therefore, the management of ETT should be a priority during the operation.

\section{Keywords}

Anesthesia, Endotracheal Tube, Displacement, Fixation, Questionnaires

\section{Introduction}

Securing the endotracheal tube (ETT) following intubation is a routine procedure during general anesthesia with tracheal intubation. Proper fixation of the ETT is crucial for effective ventilation during general anesthesia while minimizing potential complications due to ETT displacement. Displacement of the ETT can result in endobronchial intubation and accidental extubation [1]. If unrecognized, endobronchial intubation can lead to hypoxemia caused by atelectasis formation in the unventilated lung, and hyperinflation and barotrauma with the development of pneumothorax of the intubated lung [2]. Accidental extubation can lead to serious complications, such as laryngeal injury, vocal cord injury, aspiration, respiratory arrest, arrhythmias, hypoxemia, hypotension, cardiac arrest, anoxic brain injury, or even death [3]-[8].

Although many methods of securing ETT, including adhesive tapes, sutures, silk ties, commercial ETT holders, umbilical cord clamps, or a combination of these techniques have been used to reduce the displacement of ETT, the best method of securing ETT remains a controversial issue [9]-[14]. Additionally, anesthesia textbooks do not describe how to fix ETT in detail. The case reports of accidental extubation during general anesthesia can still be found in recent years [7] [15] [16] [17] [18] [19], however, the cases of ETT displacement and its consequences might be underestimated in the literature.

Therefore, the objective of the surveys was to investigate how many anesthesiologists had ever experienced the ETT displacement and its consequences during anesthesia, and the surveys were performed in 2014 and 2020 respectively, in China. The results for 2014 with those for 2020 were compared to investigate the advance in ETT fixation methods. This survey will provide preliminary information on ETT fixation methods, ETT displacement frequency and the possible factors to cause ETT displacement.

\section{Methods}

\subsection{Questionnaire Design}

The relevant literature was searched through the PubMed medical literature retrieval system with keywords, such as "accidental extubation", "endotracheal tube", "displacement", "fixation", and "questionnaire survey". According to the results of the literature search and the experience of ETT securement in the clinic, we designed the questionnaire. 
The questionnaire consisted of twenty questions, which involved the characteristics of respondents, the ETT fixation methods, the ETT displacement and its consequences experienced by the anesthesiologists, and the factors influencing the anesthesiologists to determine the method of fixing the ETT (for details, see supplementary materials).

\subsection{Respondents and Investigated Methods}

One hundred and eighty questionnaires were randomly distributed to anesthesiologists who participated in the 22nd annual meeting of Chinese Society of Anesthesiology in Chengdu, China on September 12th and 13th, 2014. The questionnaires were promptly returned after being answered. In 2020, the questionnaires were distributed and collected through the "questionnaire star" online questionnaire survey platform via WeChat, and 378 anesthesiologists from twenty-eight provinces in China volunteered to complete the questionnaires from August 28th to 30th.

All of the respondents should have more than one year of clinical anesthesia working experience. Interns and anesthesiologists assistants were excluded from this survey. Before completing and submitting the survey, the anesthesiologists were informed about their consent to participate in the survey and authorized the researchers to analyze their responses. The anesthesiologists were informed that no identifiable information would be published or released.

\subsection{Data Collection}

The questionnaires were collected and stored in department of anesthesia, the Sixth Affiliated Hospital, Sun Yat-sen University. The valid questionnaires were selected if they met the following requirements. First, the written responses to all of the questions were legible; second, there were no mistakes among the answers; third, there were no inherent contradictions among the answers.

\subsection{Statistical Analysis}

The categorical variables were presented as number and percent. Continuous variables were presented as mean \pm standard deviation (SD). Comparison of working experience between respondents in 2014 and 2020 was assessed with the Kruskal-Wallis test. Comparison of mean cases of ETT displacement experienced by respondents between 2014 and 2020 was assessed with the Mann-Whitney U test. Chi-square test with correction for continuity was used to compare the influence of surgical site and position on ETT fixation between 2014 and 2020. Comparison of other categorical variables was assessed with the chi-square test. Logistic regression was used to analyze the relationship between ETT displacement and professional titles, fixing ETT by themselves or not, fixation materials, fixation methods, whether to place bite block, fixation methods after bite block, whether to consider the surgical site and position, and whether to consider the age. The forward method was used as the screening method of the independent variable. Statistical analysis was performed by SPSS 16.0 (SPSS Inc., USA). For 
all analyses, the two-tailed $P$ value of less than 0.05 was considered statistically significant.

\section{Results}

\subsection{Characteristics of the Respondents}

A total of 568 questionnaires were collected, of which 541 were valid (valid response rate $95.2 \%)$. The respondents were from 28 provinces in China. The province distribution of the respondent's hospital is shown in Figure 1.

The constituent ratios of hospital category, hospital grade, professional title, work experience, and cases of endotracheal intubation performed per month are shown in Table 1 . Approximately $60 \%$ of respondents had the professional title

Table 1. The characteristics of respondents.

\begin{tabular}{|c|c|c|c|c|}
\hline Variables & All respondents & $\begin{array}{l}\text { Respondents } \\
\text { in } 2014\end{array}$ & $\begin{array}{l}\text { Respondents } \\
\text { in } 2020\end{array}$ & $P$ value \\
\hline & $n=541$ & $n=179$ & $n=362$ & \\
\hline \multicolumn{5}{|l|}{ Hospital category } \\
\hline General hospital & $435(80.4 \%)$ & $144(80.4)$ & $291(80.4 \%)$ & 0.987 \\
\hline Specialized hospital & $106(19.6 \%)$ & $35(19.6 \%)$ & $71(19.6 \%)$ & \\
\hline \multicolumn{5}{|l|}{ Hospital grade* } \\
\hline Grade 3 class A & $409(75.6 \%)$ & $146(81.6 \%)$ & $263(72.7 \%)$ & 0.023 \\
\hline Below grade 3 class A & $132(24.4 \%)$ & $33(18.4 \%)$ & $99(27.3 \%)$ & \\
\hline \multicolumn{5}{|l|}{ Professional titles* } \\
\hline Chief physician & $22(4.1 \%)$ & $16(18.9 \%)$ & $6(1.7 \%)$ & 0.010 \\
\hline Associate chief physician & $115(21.3 \%)$ & $41(22.9 \%)$ & $74(20.4 \%)$ & \\
\hline Attending physician & $188(34.7 \%)$ & $55(30.7 \%)$ & $133(36.7 \%)$ & \\
\hline Resident physician & $216(39.9 \%)$ & $67(37.4 \%)$ & $149(41.2 \%)$ & \\
\hline \multicolumn{5}{|l|}{ Work experience (years) } \\
\hline $1-5$ & $197(36.4 \%)$ & $66(36.9 \%)$ & $131(36.2 \%)$ & 0.305 \\
\hline $6-10$ & $112(20.7 \%)$ & $35(19.6 \%)$ & $77(21.3 \%)$ & \\
\hline $11-15$ & $135(25.0 \%)$ & $31(17.3 \%)$ & $104(28.7 \%)$ & \\
\hline $16-20$ & $57(10.5 \%)$ & $29(16.2 \%)$ & $28(7.7 \%)$ & \\
\hline$>20$ & $40(7.4 \%)$ & $18(10.1 \%)$ & $22(6.1 \%)$ & \\
\hline \multicolumn{5}{|l|}{$\begin{array}{c}\text { The case of endotracheal tube } \\
\text { used per month }\end{array}$} \\
\hline $1-25$ & $92(17.0 \%)$ & $25(14 \%)$ & $67(18.5 \%)$ & 0.214 \\
\hline $26-50$ & $221(40.9 \%)$ & $66(36.9 \%)$ & $155(42.8 \%)$ & \\
\hline $51-75$ & $97(17.9 \%)$ & $37(20.7 \%)$ & $60(16.6 \%)$ & \\
\hline $76-100$ & $95(17.6 \%)$ & $38(21.2 \%)$ & $57(15.7 \%)$ & \\
\hline$>100$ & $36(6.6 \%)$ & $13(7.3 \%)$ & $23(6.4 \%)$ & \\
\hline
\end{tabular}

Data are expressed as the number of the respondents (percentage). Compared variables between 2014 and $2020,{ }^{*} P<0.05$. 


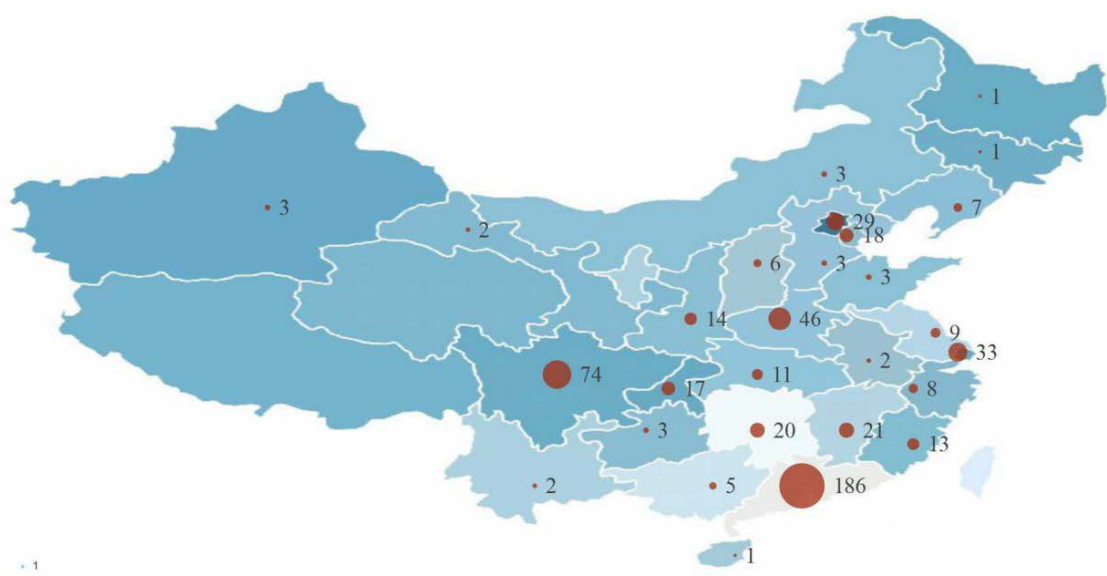

Figure 1. The map distribution of respondents in China. The area of the red dots represents the number of respondents in this province. Number of the respondents is listed at the right of the red dot.

of attending physician or higher. The constituent ratios of the respondents' professional titles between 2014 and 2020 had significant differences $(P=0.01)$, fewer chief physicians took part in 2020's survey. More than $60 \%$ of respondents had more than 5 years of work experience and $83 \%$ of respondents performed more than 25 cases of endotracheal intubations per month.

\subsection{ETT Fixation Methods in Clinical Anesthesia}

As shown in Table 2, 77.8\% of the respondents indicated that they could fix ETT by themselves after intubation. In comparison to respondents in 2014, proportionately higher numbers of respondents fixed ETT by themselves in 2020 (67.7\% vs. 82.9\%, $P<0.001$ ). Among the respondents, $90.4 \%$ indicated they routinely secured the ETT with adhesive tape, including silk medical adhesive tape (49.5\%) and plastic medical adhesive tape (40.9\%).

A total of $60.8 \%$ of respondents stated that they fixed ETT in the shape of the letter X, using two pieces of adhesive tapes of appropriate length and width, where one piece of tape was attached to one side of the cheek, wrapped around the tube two circles, and subsequently cross-fixed on the same side of the cheek, and the other piece of tape was attached to the other side of the cheek, wrapped around the tube two circles, and then cross-fixed on the same side. In comparison to respondents in 2020, proportionately higher numbers of respondents in 2014 fixed ETT in the shape of the letter $\mathrm{X}(P<0.001)$ (Table 2).

And $87.6 \%$ of the respondents stated that they usually placed a bite block after endotracheal intubation, proportionately fewer respondents place a bite block in 2020. When placing a bite block, proportionately fewer respondents first secured the ETT and then fixed the bite block with the ETT in 2014 compared to 2020 (44.1\% vs. 52.8\%, $P=0.004$ ) (Table 2).

\subsection{ETT Displacement and Consequences}

Among the respondents, 65.6\% (355/541) had experienced ETT displacement. 
Table 2. The endotracheal tube fixation status in clinical anesthesia.

\begin{tabular}{|c|c|c|c|c|}
\hline Variables & All respondents & $\begin{array}{l}\text { Respondents } \\
\text { in } 2014\end{array}$ & $\begin{array}{l}\text { Respondents } \\
\text { in } 2020\end{array}$ & $P$ value \\
\hline & $n=541$ & $n=179$ & $n=362$ & \\
\hline \multicolumn{5}{|l|}{$\begin{array}{l}\text { Fixing endotrachea tube by } \\
\text { themselves or not }\end{array}$} \\
\hline By themselves & $421(77.8 \%)$ & $121(67.7 \%)$ & $300(82.9 \%)$ & $<0.001$ \\
\hline By others under their supervision & $109(20.2 \%)$ & $54(30.2 \%)$ & $55(15.2 \%)$ & \\
\hline By others & $11(2.0 \%)$ & $4(2.2 \%)$ & $7(1.9 \%)$ & \\
\hline \multicolumn{5}{|l|}{ Fixation materials } \\
\hline Silk medical adhesive tape & $268(49.5 \%)$ & $86(48.0 \%)$ & $182(50.3 \%)$ & 0.758 \\
\hline Plastic medical adhensive tape & $221(40.9 \%)$ & $77(43.0 \%)$ & $144(39.8 \%)$ & \\
\hline $\begin{array}{c}\text { Transparent film } \\
\text { dressing + Bangage + others }\end{array}$ & $52(9.6 \%)$ & $16(9.0 \%)$ & $36(9.9 \%)$ & \\
\hline \multicolumn{5}{|l|}{ Fixation methods* } \\
\hline $\begin{array}{l}\text { Fix the endotracheal tube in the } \\
\text { shape of the letter X }\end{array}$ & $329(60.8)$ & $133(74.3 \%)$ & $196(54.1 \%)$ & $<0.001$ \\
\hline Other fixation methods & $212(39.2)$ & $46(25.7 \%)$ & $166(45.9 \%)$ & \\
\hline \multicolumn{5}{|l|}{ Placing the bite block* } \\
\hline Yes & $474(87.6 \%)$ & $165(92.2 \%)$ & $309(85.4 \%)$ & 0.023 \\
\hline No & $67(12.4)$ & $14(7.8 \%)$ & $53(14.6 \%)$ & \\
\hline \multicolumn{5}{|l|}{$\begin{array}{l}\text { Fixation methods when } \\
\text { placing a bite block }\end{array}$} \\
\hline Method a & $244(45.1 \%)$ & $97(54.2 \%)$ & $147(40.6 \%)$ & 0.004 \\
\hline Method b & $270(49.9 \%)$ & $79(44.1 \%)$ & $191(52.8 \%)$ & \\
\hline Method c & $10(1.9 \%)$ & $2(1.1 \%)$ & $8(2.2 \%)$ & \\
\hline Method d & $17(3.1 \%)$ & $1(0.6 \%)$ & $16(4.4 \%)$ & \\
\hline
\end{tabular}

Data are expressed as the number of the respondents (percentage). The shape of letter X: Using two pieces of adhesive tapes of appropriate length and width, where one piece of tape was attached to one side of the cheek, wrapped around the tube two circles, and subsequently cross-fixed on the same side of the cheek, and the other piece of tape was attached to the other side of the cheek, wrapped around the tube two circles, and then cross-fixed on the same side. Method a: fixed the bite block and tube together. Method b: First fixed the endotracheal tube and then fixed the bite block with the tube. Method c: Fixed the endotracheal tube and bite block completely separately. Method d: Only fixed the endotracheal tube, not the bite block. Compared variables between 2014 and $2020,{ }^{\star} P<0.05$.

Proportionately higher numbers of respondents in 2014 had experienced the ETT displacement compared with respondents in $2020(72.1 \%$ vs. $62.4 \%, P=$ 0.026) (Figure 2). The mean cases of ETT displacement experienced by respondents in 2020 were more than that in 2014 (4.7 \pm 5.4 vs. $3.5 \pm 4.4, P<0.001)$. A minority of the respondents $(23 / 541,4.3 \%)$ indicated that they had experienced serious consequences caused by ETT displacement, including hypoxemia (7/541), atelectasis (9/541), cardiac arrest (2/541), death (2/541) and other complications (3/541) (Figure 3). 
No ETT displacement $\square$ ETT displacement

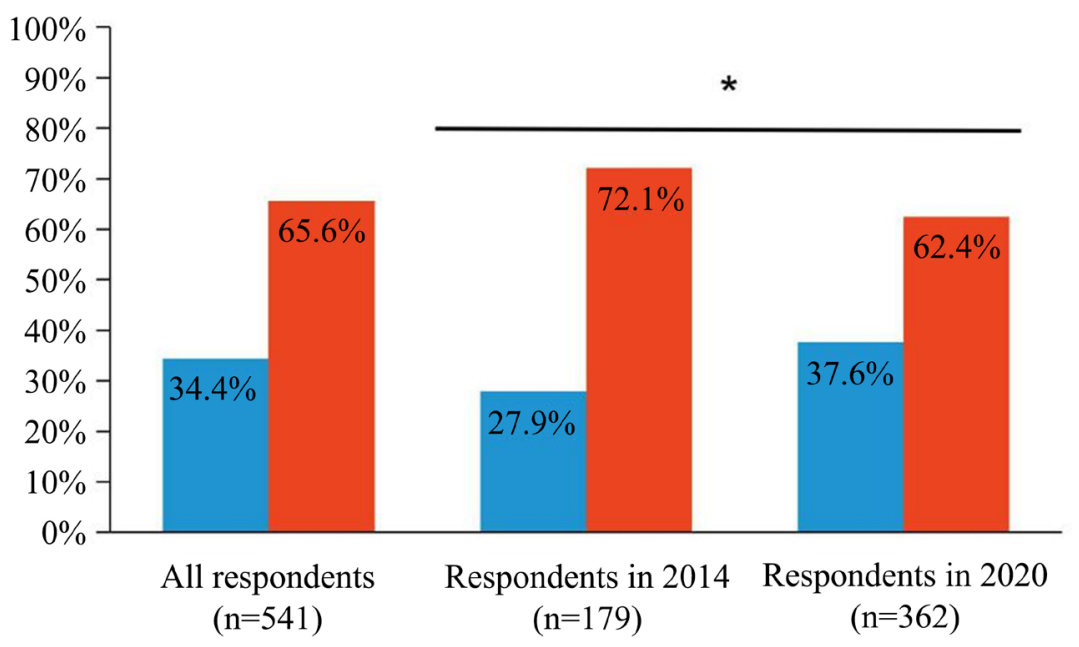

Figure 2. The percentage of respondents with ETT displacement or no ETT displacement. ETT: Endotracheal tube. ${ }^{*} P<0.05$.

YES $\square \mathrm{NO}$ NS

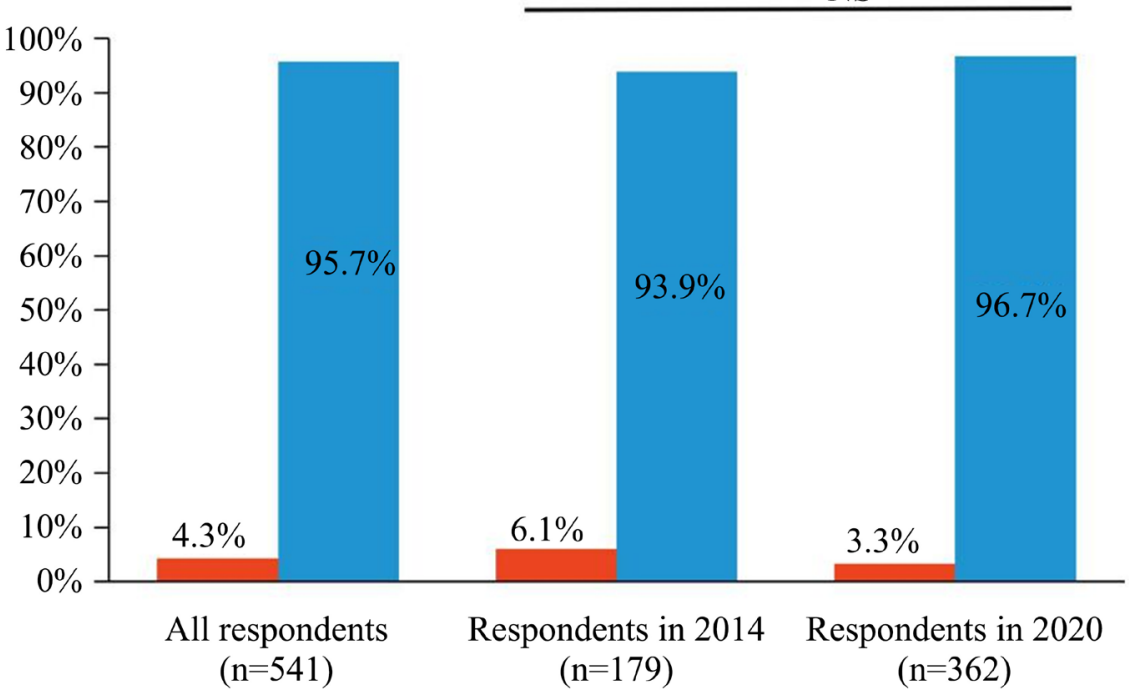

Figure 3. The percentage of respondents experienced serious consequences or not due to endotracheal tube displacement. NS: No significant.

\subsection{The Factors Influencing the Anesthesiologists to Determine the Method of ETT Fixation}

Among the respondents, $97.8 \%$ stated that they considered the influence of surgical site and position on ETT fixation, and $77.1 \%$ took the age of patients into account when securing the ETT. Proportionately higher numbers of respondents considered the influence of age on ETT fixation in 2014 compared with respondents in $2020(P<0.001)$ (Table 3$)$. The fixation materials used in head and neck surgery, prone surgery and pediatric surgery are shown in Table 3.

As for patients in the supine position underwent except head and neck surgery, 
Table 3. The factors influencing the anesthesiologist to determine the method of fixing the endotrachea tube.

\begin{tabular}{ccccc}
\hline Variables & All respondents & $\begin{array}{c}\text { Respondents } \\
\text { in } 2014\end{array}$ & $\begin{array}{c}\text { Respondents } \\
\text { in } 2020\end{array}$ & $P$ value \\
\hline Influence of surgical site and position & $n=541$ & $n=179$ & $n=362$ & \\
Consider & $529(97.8 \%)$ & $177(98.9 \%)$ & $352(97.2 \%)$ & 0.362 \\
Not consider & $12(2.2 \%)$ & $2(1.1 \%)$ & $10(2.8 \%)$ & \\
Influence of age & $n=541$ & $n=179$ & $n=362$ & \\
Consider & $417(77.1 \%)$ & $153(85.5 \%)$ & $264(72.9 \%)$ & 0.001 \\
Not consider & $124(22.9 \%)$ & $26(14.5 \%)$ & $98(27.1 \%)$ & \\
Fixation material used in head and & $n=529$ & $n=177$ & $n=352$ & \\
neck surgery or prone surgery* & & & & \\
Method a & $53(10.0 \%)$ & $21(11.9 \%)$ & $32(9.1 \%)$ & 0.005 \\
Method b & $170(32.1 \%)$ & $72(40.7 \%)$ & $98(27.8 \%)$ & \\
Method c & $275(52.0 \%)$ & $73(41.2 \%)$ & $202(57.4 \%)$ & \\
Method d & $31(5.9 \%)$ & $11(6.2 \%)$ & $20(5.7 \%)$ & \\
Fixation material & $n=417$ & $n=153$ & $n=264$ & \\
used in pediatric surgery & $100(24.0 \%)$ & $29(19.0 \%)$ & $71(26.9 \%)$ & 0.132 \\
Method a & $138(33.1 \%)$ & $59(38.6 \%)$ & $79(29.9 \%)$ & \\
Method b & $142(34.0 \%)$ & $54(35.3 \%)$ & $88(33.3 \%)$ & \\
Method c & $37(8.9 \%)$ & $11(7.2 \%)$ & $26(9.8 \%)$ & \\
Method d & & & & \\
\hline
\end{tabular}

Data are expressed as the number of the respondents (percentage). Material a: Same as the materials for fixing general endotracheal tube; Material b: Reinforce tube with adhensive tape; Material c: Reinforce tube with transparent film dressing; Material d: Reinforce tube with other materials. ${ }^{\star} P<0.05$.

the primary cause of ETT displacement is shown in Figure 4. The constituent ratios of the primary cause of ETT displacement between 2014 and 2020 were significantly different $(P<0.05)$ (Figure 4$)$.

\subsection{Logistic Analysis Results of Possible Factors to Cause ETT Displacement Experienced by Respondents}

To analysis, the possible factors to cause the ETT displacement, respondents with and without ETT displacement were compared. Multivariate logistic regression model was established by including the professional title, fixing endotrachea tube by themselves or not, fixation materials, fixation methods, whether to place bite block, fixation methods after bite block, whether to consider the surgical site and position, and whether to consider age. The results shown that decrease in the professional title significantly increases the risk of ETT displacement (attending physician: $\mathrm{OR}=2.08,95 \% \mathrm{CI} 1.27-3.42, P=0.004$; resident physician: $\mathrm{OR}=2.41,95 \% \mathrm{CI} 1.56-3.71, P<0.001)$. The risk of ETT displacement was significantly increased without the placement of bite block (OR $=1.90,95 \%$ CI 1.11 - 3.25, $P=0.02)$, without the consideration of surgical site or position ( $\mathrm{OR}=$ $3.57,95 \%$ CI $1.01-12.62, P=0.048$ ), and without the consideration of age (OR $=1.89,95 \%$ CI $1.24-2.89, P=0.003$ ) (Table 4 ). 
Table 4. Logistic analysis results of the possible factors to cause endotracheal tube displacement experienced by responders.

\begin{tabular}{|c|c|c|c|c|c|c|c|}
\hline \multirow[b]{2}{*}{ variables } & \multirow[b]{2}{*}{ Coefficient } & \multirow[b]{2}{*}{$\begin{array}{l}\text { Standard } \\
\text { error }\end{array}$} & \multirow[b]{2}{*}{ Wald $\chi^{2}$} & \multirow[b]{2}{*}{$\mathrm{P}$} & \multirow[b]{2}{*}{ OR } & \multicolumn{2}{|c|}{$95 \%$ CI } \\
\hline & & & & & & $\begin{array}{c}\text { lower } \\
95 \% \mathrm{CI}\end{array}$ & $\begin{array}{c}\text { lower } \\
95 \% \mathrm{CI}\end{array}$ \\
\hline \multicolumn{8}{|l|}{ Professional titles } \\
\hline \multicolumn{8}{|l|}{ Chief physician* } \\
\hline Associate chief physician & 0.69 & 0.49 & 1.97 & 0.16 & 1.99 & 0.76 & 5.24 \\
\hline Attending physician & 0.73 & 0.25 & 8.45 & 0.004 & 2.08 & 1.27 & 3.42 \\
\hline Resident physician & 0.88 & 0.22 & 15.82 & $<0.001$ & 2.41 & 1.56 & 3.71 \\
\hline \multicolumn{8}{|l|}{ Placing the bite block } \\
\hline \multicolumn{8}{|l|}{ Yes $^{*}$} \\
\hline No & 0.64 & 0.28 & 5.40 & 0.02 & 1.90 & 1.11 & 3.25 \\
\hline \multicolumn{8}{|c|}{ Consider the influence of surgical site and position } \\
\hline \multicolumn{8}{|l|}{ Yes $^{*}$} \\
\hline No & 1.27 & 0.65 & 3.89 & 0.048 & 3.57 & 1.01 & 12.62 \\
\hline \multicolumn{8}{|c|}{ Consider the influence of age } \\
\hline \multicolumn{8}{|l|}{ Yes $^{*}$} \\
\hline No & 0.64 & 0.216 & 8.67 & 0.003 & 1.89 & 1.24 & 2.89 \\
\hline
\end{tabular}

*represented reference category. OR: Odds ratio, CI: Confidence interval.

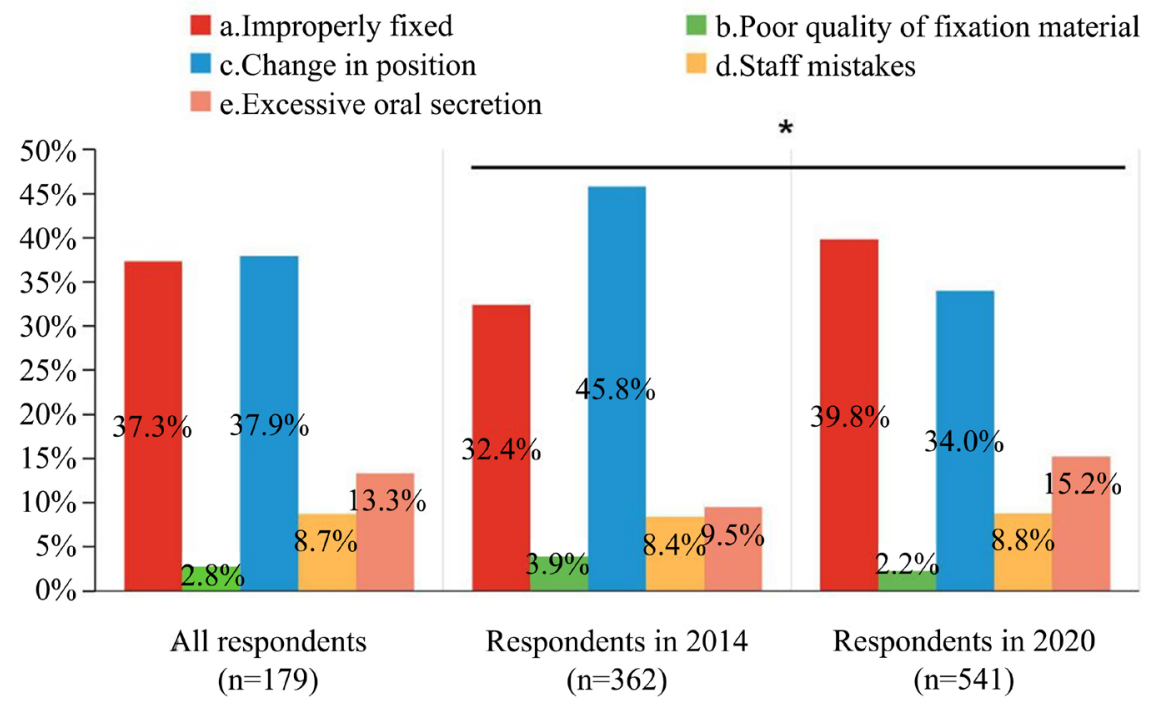

Figure 4. The primary cause of endotracheal tube displacement in the supine position with except head and neck surgery during general anesthesia, ${ }^{\star} P<0.05$.

\section{Discussion}

The surveys indicate that a majority of anesthesiologists in China experienced ETT displacement during general anesthesia in 2014 and 2020. A minority of anesthesiologists even experienced cardiac arrest and death of patients due to 
ETT displacement. A majority of the respondents secured ETT in the shape of the letter $\mathrm{X}$ with adhesive tape. A majority of respondents considered the influence of surgical site, position, and age on securing the ETT, after which most of them would reinforce the ETT with other materials.

ETT displacement, especially accidental extubation, is a potentially life-threatening complication that can occur following intubation. However, literature on the incidence of accidental extubation and ETT displacement in surgical patients with general anesthesia remains limited. In our survey, among all participants, 65.6\% had experienced ETT displacement, and 4.3\% had experienced serious complications such as hypoxemia, cardiac arrest, or death due to ETT displacement. Although the incidence of ETT displacement experienced by anesthesiologists decreased by $9.7 \%$ in 2020 compared with that in 2014, it was still as high as $62.4 \%$. A previous study has shown that $12 \%$ of the airway cases in the anesthesia closed claims analysis were caused by premature extubation [20]. In clinical anesthesia, preventing the ETT displacement and reducing the complications related to ETT displacement should be a priority.

There are many risk factors for ETT displacement in general anesthesia during surgery. Previous studies have shown that head and neck movement could lead to unexpected tube displacement [21] [22] [23] and patients who underwent a supine-to-prone position change were more likely to experience ETT displacement [24]. Additionally, children younger than 2 years presented greater unplanned extubation rates than children over 2 years [25]. Another study found that unplanned extubations were more common in children who were younger than 5 years compared with older children [26]. In our survey, lower profession title, without placing the bite block, without the consideration of surgical site or position and without the consideration of age were the risk factors of ETT displacement. So a majority of respondents had considered the influence of surgical site, position, and age on securing ETT. As such, a majority of respondents indicated that they reinforced the ETT with adhesive tape, transparent film dressing, or other materials.

Previous studies on the optimum fixation material and method have yielded contradictory results [9] [12] [13] [27]. Our survey found that there were differences in fixation methods between 2014 and 2020, the fixation materials did not change significantly. Adhesive tape was the most commonly used fixation material in clinical practice and only a minority of respondents routinely used other materials, including transparent film dressing, bandages, sutures, ETT-holders. The proportion of respondents who stated that improperly fixing ETT was the primary cause of ETT displacement was higher than that who indicated that poor quality of fixation materials led to ETT displacement $37.3 \%$ and $2.8 \%$, respectively). In the opinion of respondents, the fixation methods were more critical than the fixation materials for preventing ETT displacement. Our survey showed a majority of respondents secured ETT with adhesive tape in the shape of the letter $\mathrm{X}$. In addition, the fixation method in the shape of letter $\mathrm{H}$, the fixa- 
tion method in the shape of the letter Y, and other methods with adhesive tape are often used in clinical practice [28] [29]. The optimum fixation method needs to be explored.

So far, there are few surveys to investigate the ETT displacement experienced by anesthesiologists and consequences during general anesthesia. Among the respondents, $63.1 \%$ had been practicing for 6 or more years, and $60.1 \%$ had a professional title of attending physician or higher. All of the respondents were active in anesthesia clinical work, and $83 \%$ of the respondents performed more than 25 cases of ETT per month, indicating a high level of reliability of the questionnaire responses. Meanwhile, all the questionnaires were filled out anonymously, so the respondents did not have any relevant concerns. These measures ensured the authenticity and reliability of this survey.

The major limitation of this study was that the cases and the consequences of ETT displacement were reported solely by the memory of the respondent, and there might be some discrepancy between the respondents' memory and the clinic records. Additionally, except for work experience and professional titles, other factors such as gender or educational background, might also affect the fixation of ETT, which we hope to address in our future work. Moreover, the differences in the survey methods may have led to differences in the characteristics of respondents. Compared with the online survey, a higher proportion of face-to-face respondents came from grade 3 class A hospitals and were chief physicians, which may have led to differences in the incidence of ETT displacement experienced by respondents between 2014 and 2020 .

\section{Conclusion}

In conclusion, a majority of anesthesiologists experienced ETT displacement, which may result in serious complications during general anesthesia. Therefore, management of the ETT should be paid more attention during the operation.

\section{Acknowledgements}

We thank Hongbin Feng, Zijia Li, Zhinan Zheng, Shanmei Wu, Nanrong Zhang and all other colleagues in our department for their assistance in the collection of questionnaires. We thank the respondents for their participation in the investigation.

\section{Authors' Contributions}

Sanqing Jin designed the study and supervised the whole process of the study and revised the manuscript. Dongxue Li and Tongfeng Luo collected and analyzed the data, and wrote the manuscript. Chuling Liu and Xi Hong checked and analyzed the data. All authors read and approved the final version.

\section{Conflicts of Interest}

The authors declare no conflicts of interest regarding the publication of this paper. 


\section{References}

[1] Sugiyama, K. and Yokoyama, K. (1996) Displacement of the Endotracheal Tube Caused by Change of Head Position in Pediatric Anesthesia: Evaluation by Fiberoptic Bronchoscopy. Anesthesia \& Analgesia, 82, 251-253. https://doi.org/10.1097/00000539-199602000-00006

[2] Owen, R.L. and Cheney, F.W. (1987) Endobronchial Intubation: A Preventable Complication. Anesthesiology, 67, 255-257. https://doi.org/10.1097/00000542-198708000-00019

[3] Boulain, T. (1998) Unplanned Extubations in the Adult Intensive Care Unit: A Prospective Multicenter Study. Association Des Réanimateurs Du Centre-Ouest. https://doi.org/10.1164/ajrccm.157.4.9702083

[4] Birkett, K.M., Southerland, K.A. and Leslie, G.D. (2005) Reporting Unplanned Extubation. Intensive and Critical Care Nursing, 21, 65-75. https://doi.org/10.1016/j.iccn.2004.07.012

[5] Kambestad, K.K., Huack, A., Nair, S., Chapman, R., Chin, S., Langga, L., et al. (2019) The Adverse Impact of Unplanned Extubation in a Cohort of Critically Ill Neonates. Respiratory Care, 64, 1500-1507. https://doi.org/10.4187/respcare.06721

[6] Kiekkas, P., Aretha, D., Panteli, E., Baltopoulos, G.I. and Filos, K.S. (2013) Unplanned Extubation in Critically Ill Adults: Clinical Review. Nursing in Critical Care, 18, 123-134. https://doi.org/10.1111/j.1478-5153.2012.00542.x

[7] Sinha, P.K., Koshy, T. and Sivakumar, P. (2008) Nasogastric Tube Withdrawal: An Unusual Cause of Accidental Extubation and Near Cardiac Arrest in an Infant. Journal of Cardiothoracic and Vascular Anesthesia, 22, 105-107. https://doi.org/10.1053/j.jvca.2007.02.002

[8] Mort, T.C. (1998) Unplanned Tracheal Extubation Outside the Operating Room: A Quality Improvement Audit of Hemodynamic and Tracheal Airway Complications Associated with Emergency Tracheal Reintubation. Anesthesia \& Analgesia, 86, 1171-1176. https://doi.org/10.1213/00000539-199806000-00006

[9] Buckley, J.C., Brown, A.P., Shin, J.S., Rogers, K.M. and Hoftman, N.N. (2016) A Comparison of the Haider Tube-Guard ${ }^{\circledR}$ Endotracheal Tube Holder Versus Adhesive Tape to Determine if this Novel Device Can Reduce Endotracheal Tube Movement and Prevent Unplanned Extubation. Anesthesia \& Analgesia, 122, 1439-1443. https://doi.org/10.1213/ANE.0000000000001222

[10] Wagner, J.L., Shandas, R. and Lanning, C.J. (2014) Extubation Force Depends upon Angle of Force Application and Fixation Technique: A Study of 7 Methods. BMC Anesthesiology, 14, 74. https://doi.org/10.1186/1471-2253-14-74

[11] Da, S.P. and Fonseca, M.C. (2012) Unplanned Endotracheal Extubations in the Intensive Care Unit: Systematic Review, Critical Appraisal, and Evidence-Based Recommendations. Anesthesia \& Analgesia, 114, 1003-1014. https://doi.org/10.1213/ANE.0b013e31824b0296

[12] Shimizu, T., Mizutani, T., Yamashita, S., Hagiya, K. and Tanaka, M. (2011) Endotracheal Tube Extubation Force: Adhesive Tape versus Endotracheal Tube Holder. Respiratory Care, 56, 1825-1829. https://doi.org/10.4187/respcare.00954

[13] Owen, R., Castle, N., Hann, H., Reeves, D., Naidoo, R. and Naidoo, S. (2009) Extubation Force: A Comparison of Adhesive Tape, Non-Adhesive Tape and a Commercial Endotracheal Tube Holder. Resuscitation, 80, 1296-1300.

https://doi.org/10.1016/j.resuscitation.2009.08.007

[14] Carlson, J., Mayrose, J., Krause, R. and Jehle, D. (2007) Extubation Force: Tape ver- 
sus Endotracheal Tube Holders. Annals of Emergency Medicine, 50, 686-691. https://doi.org/10.1016/j.annemergmed.2007.05.013

[15] Arya, S., Kaushal, A., Talawar, P. and Varnitha, M.S. (2019) Accidental Extubation during Parotid Surgery: An Unusual But Dreaded Complication. Indian Journal of Anaesthesia, 63, 1043-1044. https://doi.org/10.4103/ija.IJA_532_19

[16] Thampi, S.M., Thomas, S. and Rai, E. (2018) Intra-Operative Accidental Extubation-An Unexpected Complication of the Flexo-Metallic Tube. Journal of Anaesthesiology Clinical Pharmacology, 34, 414-415.

[17] Baduni, N., Sanwal, M.K. and Jain, A. (2013) Intubating Laryngeal Mask Airway-A Lifesaver during Accidental Intraoperative Extubation in a Case of Difficult Airway. Anesthesia, Essays and Researches, 7, 139-140. https://doi.org/10.4103/0259-1162.114025

[18] Gaszynski, T. (2019) Intubation in Prone Position Using AirTraq Avant Videolaryngoscope. Journal of Clinical Monitoring and Computing, 33, 173-174. https://doi.org/10.1007/s10877-018-0128-1

[19] O’Leary, A.M., Sandison, M.R. and Roberts, K.W. (2008) An Unusual Cause of Accidental Extubation. Journal of Clinical Anesthesia, 20, 486.

https://doi.org/10.1016/j.jclinane.2008.05.008

[20] Cheney, F.W., Posner, K.L., Lee, L.A., Caplan, R.A. and Domino, K.B. (2006) Trends in Anesthesia-Related Death and Brain Damage: A Closed Claims Analysis. Anesthesiology, 105, 1081-1086. https://doi.org/10.1097/00000542-200612000-00007

[21] Tailleur, R., Bathory, I., Dolci, M., Frascarolo, P., Kern, C. and Schoettker, P. (2016) Endotracheal Tube Displacement during Head and Neck Movements. Observational Clinical Trial. Journal of Clinical Anesthesia, 32, 54-58. https://doi.org/10.1016/j.jclinane.2015.12.043

[22] Kim, J.T., Kim, H.J., Ahn, W., Kim, H.S., Bahk, J.H., Lee, S.C., et al. (2009) Head Rotation, Flexion, and Extension Alter Endotracheal Tube Position in Adults and Children. Canadian Journal of Anesthesia, 56, 751-756. https://doi.org/10.1007/s12630-009-9158-y

[23] Jordi, R.E., Von Ungern-Sternberg, B.S., Keller, K., Frei, F.J. and Erb, T.O. (2008) The Impact of Head Position on the Cuff and Tube Tip Position of Preformed Oral Tracheal Tubes in Young Children. Anaesthesia, 63, 604-609. https://doi.org/10.1111/j.1365-2044.2008.05440.x

[24] Minonishi, T., Kinoshita, H., Hirayama, M., Kawahito, S., Azma, T., Hatakeyama, N., et al. (2013) The Supine-to-Prone Position Change Induces Modification of Endotracheal Tube Cuff Pressure Accompanied by Tube Displacement. Journal of Clinical Anesthesia, 25, 28-31. https://doi.org/10.1016/j.jclinane.2012.05.007

[25] Sadowski, R., Dechert, R.E., Bandy, K.P., Juno, J., Bhatt-Mehta, V., Custer, J.R., et al. (2004) Continuous Quality Improvement: Reducing Unplanned Extubations in a Pediatric Intensive Care Unit. Pediatrics, 114, 628-632. https://doi.org/10.1542/peds.2003-0735-L

[26] Da, S.P., de Aguiar, V.E., Neto, H.M. and de Carvalho, W.B. (2008) Unplanned Extubation in a Paediatric Intensive Care Unit: Impact of a Quality Improvement Programme. Anaesthesia, 63, 1209-1216. https://doi.org/10.1111/j.1365-2044.2008.05628.x

[27] Gardner, A., Hughes, D., Cook, R., Henson, R., Osborne, S. and Gardner, G. (2005) Best Practice in Stabilisation of Oral Endotracheal Tubes: A Systematic Review. Australian Critical Care, 18, 158, 160-165. 
https://doi.org/10.1016/S1036-7314(05)80029-3

[28] Lai, M., Inglis, G.D., Hose, K., Jardine, L.A. and Davies, M.W. (2014) Methods for Securing Endotracheal Tubes in Newborn Infants. Cochrane Database of Systematic Reviews, No. 2, CD007805. https://doi.org/10.1002/14651858.CD007805.pub2

[29] Matchett, G., Yang, J.H., Sripathi, N.R., Simpkins, L., Ruikar, K., Minhajuddin, A., et al. (2020) Characterizing the Structural Integrity of Endotracheal Tube Taping Techniques: A Simulation Study. Anesthesia \& Analgesia, 131, 544-554.

https://doi.org/10.1213/ANE.0000000000004206 


\section{Supplementary Materials}

Questionnaire of ETT displacement

Do you agree to participate?

Yes No

\section{Your basic information}

1) Your hospital

Province: City:

2) Your hospital is:

$\begin{array}{ll}\text { a) General hospital } & \text { b) Specialized hospital }\end{array}$

3) The grade of your hospital is:
a) Grade 3 class $A$
b) Grade 3 class B
c) Grade 2 class $A$
d) Grade 2 class B
e) Other grades
4) Your work experience: years

5) Your professional title:
a) Chief physician
b) Association chief physician
c) Attending physician
d) Resident physician

6) The cases of endotracheal intubation you performed per month in your memory:

\section{ETT fixation status in the clinic}

7) Whether you fixed the ETT by yourself after the endotracheal intubation?

a) Fixed the ETT by yourself

b) Fixed the ETT by others under your supervision

c) Fixed the ETT by others

8) The material for fixing the ETT:
a) Silk medical adhesive tape
b) Plastic medical adhesive tape
c) Transparent film dressing
d) Baggage
e) Others (ETT-holder)

9) Whether you usually place a bite block after endotracheal intubation?
a) Yes
b) No

10) The method for fixing the ETT with adhesive tape:

a) Fixed the ETT in the shape of the letter $\mathrm{X}^{*}$

b) Fixed the ETT in other methods

*The shape of the letter X: using two pieces of adhesive tapes of appropriate length and width, where one piece of tape was attached to one side of the cheek, wrapped around the tube two circles, and subsequently cross-fixed on the same side of the cheek, and the other piece of tape was attached to the other side of the cheek, wrapped around the tube two circles, and then cross-fixed on the same side.

11) When placing a bite block, the method that you fixed the ETT was:

a) Fixed the bite block and ETT together

b) First fixed the ETT and then fixed the bite block with ETT

c) Fixed the ETT and bite block completely separately

d) Only fixed the ETT, not the bite block

The respondents who have experienced ETT displacement and the serious consequences 
12) Did you experience the ETT displacement during your clinical anesthesia

a) Yes

b) No

13) How many cases of ETT displacement you have experienced:

14) Did you experience serious consequences caused by the ETT displacement

$\begin{array}{lll}\text { a) Yes } & \text { b) No }\end{array}$

15) The serious consequence caused by the ETT displacement you have experienced:
a) Death
b) Cardiac arrest
c) Hypoxemia
d) Atelectasis

e) Others

The factors influencing anesthesiologists to determine the method of ETT fixation.

16) Did you consider the influence of the surgical site and position on fixing the ETT?
a) Yes
b) No

17) The material for fixing the ETT in patients who underwent head and neck surgery or in the prone position

a) The same as the material for fixing general ETT.

b) Reinforce with adhesive tape

c) Reinforce with a transparent film dressing.

d) Reinforce with other materials

18) Did you consider the influence of the age of the patient on fixing the ETT?

$\begin{array}{lll}\text { a) Yes } & \text { b) No }\end{array}$

19) The material for fixing the ETT in pediatric

a) The same as the material for fixing general ETT.

b) Reinforce with adhesive tape.

c) Reinforce with a transparent film dressing.

d) Reinforce with other materials

20) In your opinion, the primary cause of ETT displacement in patients in the supine position with except head and neck surgery:
a) Improperly fixed
b) Poor quality of fixation materials
c) A change in position
d) Staff mistakes
e) Excessive oral secretion 